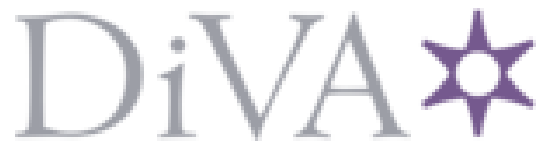

http://www.diva-portal.org

Preprint

This is the submitted version of a paper published in Journal of Design Research.

Citation for the original published paper (version of record):

Panarotto, M. (2020)

Using models as boundary objects in early design negotiations: analysis and implications for decision support systems

Journal of Design Research, (2/3/4): 214-237

https://doi.org/10.1504/JDR.2019.105757

Access to the published version may require subscription.

N.B. When citing this work, cite the original published paper.

Permanent link to this version:

http://urn.kb.se/resolve?urn=urn:nbn:se:bth-19349 


\title{
Using models as boundary objects in early design negotiations: analysis and implications for decision support systems
}

\author{
ABSTRACT: \\ The manufacturers' increased responsibility over the product lifecycle drives the \\ need to emphasise more downstream lifecycle dimensions in the early design \\ phases. One common strategy to deal with this is to enrich modelling and \\ simulation techniques embedded in decision support systems. However, \\ downstream dimensions entail a number of tacit concepts that make them \\ difficult to trade against more traditional engineering objectives. \\ This research studied through individual interviews how different disciplines use \\ models to negotiate design trade-offs. By analysing negotiations among six \\ disciplines, references to models were categorised according to whether models \\ supported or hampered the duration of trade-off identification and how they \\ impacted the duration of trade-off resolution. \\ The results point to the difficulty of applying downstream lifecycle issues earlier \\ in the design process because of the characteristics of the models that are used. \\ The study provides a list of characteristics promoting and limiting the use of four \\ models as boundary objects during early design negotiations (CAD models, \\ simulation results, Total Cost of Ownership and decision matrices). \\ The cross-analysis of these characteristics provides insights into how models \\ need to be organised and synthesised with traditional and novel methods in \\ decision support systems.
}

Keywords: collaborative design; decision-making; interdisciplinarity; product development; design models. 


\section{Introduction}

The shift towards a circular economy (Bocken et al., 2016) and 'servitization' (Tan et al., 2010), implies that all the risk related to the product maintenance and availability lies with the manufacturer (Isaksson et al., 2009). This drives companies to increase the importance of 'downstream' lifecycle properties (e.g., serviceability and remanufacturability) since the early design phases (Charnley et al., 2011). However, such properties entail a number of tacit concepts that make them difficult to trade against more traditional engineering objectives (e.g., functionality, weight, and structural robustness) that are instead easier to model, simulate, and optimise (Raudberget et al., 2015). As a consequence, important lifecycle properties run the risk of being neglected or down-prioritised during early design trade-offs (Isaksson et al., 2009), which can negatively affect function delivery and quality.

The ability to successfully trade off between diverse objectives - emphasising downstream lifecycle properties - is of major importance for industry today. This ability is generally linked to the systematic use of modelling and simulation techniques (e.g., Hazelrigg, 1998; Kokkolaras et al., 2004; Kipouros \& Isaksson, 2016) organised within decision support systems (Sacks et al., 2010; White et al., 2015). There is currently a growing interest in how to configure these environments for the early design phases (Chandrasegaran et al., 2013; Schleich et al., 2017). However, not all information can be readily available in early design (Ullman, 2003), and successful decisions are also dependent on the effective negotiation between the stakeholders (Bucciarelli, 2002). There is a need to increase the understanding of how practitioners belonging to different disciplines use established model-based supports in practice to make the case for a particular design goal. This research has focused on the following research question: 
What are the characteristics that promote or constrain the use of models as decision supports for early design negotiations?

Knowing this can provide insights into what factors should be taken into account when organizing and synthesizing models in collaborative decision-support systems (White et al., 2015). This study connects to the discussion about the role of models during negotiations between identified stakeholders (Barley et al., 2012), which are often characterized around the theoretical construct of 'boundary objects' (Star \& Griesemer, 1989). This paper provides a qualitative explanation of how "downstream" lifecycle issues run the risk to be neglected (or down-prioritised) during early design trade-offs, because of the models different disciplines are (or are not) able to use in at different points in time.

\section{Theoretical framework}

Ideally, decision-making should be based on rational choices (Simon, 1979). Models and simulations are potential sources for rational decision-making because they help to predict the future impact of a solution (Power \& Sharda, 2007). In practical situations, however, rational decision-making is rare. Rationality becomes bounded when not all alternatives are known, when external factors cannot be managed, or when it is difficult to calculate consequences (Simon, 1979). Studies demonstrate how decision-makers look for satisficing choices, selecting something that is 'good enough' for the needs of the decision situation (Simon, 1972). Such a pragmatic approach to decision-making, developed around the theory of bounded rationality (Simon, 1979), forces designers to rely on the personal experiences and intuitions of the individuals present in the multidisciplinary design team (Kastensson \& Johansson, 2011). Disciplinary diversity brings benefits to the design activity, yet it comes with challenges regarding negotiation 
(Buciarelli, 2002; Kleinsmann \& Valkenburg, 2008). Designers must first identify and agree that a negotiation (or trade-off) does in fact exist (Thibaut \& Walker, 1975). This trade-off identification stage can take time or might not occur at all (Iorio \& Taylor, 2014). If designers agree that a trade-off exists, they need to engage in developing a strategy for levelling such incompatibility (i.e., trade-off resolution stage; Iorio \& Taylor, 2014). The trade-off resolution stage can also take time, and such delays negatively impact the decision-making process (Carlile 2002; p. 541). Investigating the both trade-off identification as well as the and trade-off resolution stages of a negotiation process can reveal insights about the efficacy of representations and models in collaborative work (Iorio \& Taylor, 2014).

\subsection{The role of models and representations on design negotiations}

Designers often negotiate with model-based supports to do their reasoning (Larsson, 2003). While many definitions exist about what a model is, this research used the definition given by Carlile (2002; p. 541): 'objects or models are simple or complex representations that can be observed and then used across different functional settings. Objects or models (i.e., sketches, assembly drawings, parts, prototype assemblies, mock-ups, and computer simulations) depict or demonstrate current or possible "form, fit, and function" of the differences and dependencies identified at the boundary'. This definition, although general, considers models not only as a means to compute a set of input to produce a set of output (i.e., computational models) but also as 'useful means of understanding and interacting with both products and processes' (Eckert \& Stacey, 2010), thus recognising their representational value.

Despite the benefits of using models for solving trade-offs, this approach can also hinder the negotiation process (Flanagan et al., 2007). Carlile (2002) demonstrated how individuals create representations within their own disciplines. Errors and delays may 
occur when professionals share models with other disciplines. As these representations represent mainly the perspectives of the discipline that created them, it is difficult for other disciples to visualise their own perspectives and concerns within the same representations. To avoid these communication bottlenecks (Eckert, 2001), much of the literature stresses the notion of 'boundary objects', which identifies the types of representations that have 'different meanings in different social worlds but their structure is common enough to more than one world to make them recognisable as a means of translation' (Star \& Griesemer, 1989: p. 393). Boundary objects manage complexity since they reduce the instantaneous cognitive load during decision-making (Richards et al., 2007) and also serve to connect one design effort to the next, serving as boundary objects in time (Boujut \& Laureillard, 2002). Effective boundary objects 'do not need to be accurate to be useful' (Star, 2010: p. 613), as long as they enable people to share knowledge and find common ground. As Star \& Griesemer (1989) pointed out, boundary objects contain sufficient detail to be understandable by both parties, but at the same time, neither party understands the full context of use by the other.

Research has provided useful insights into the role of design models as boundary objects. Many studies have focused on how models support trade-offs between the functional and geometrical properties of a design. For example, Henderson (1991), Perry and Sanderson (1998), and Barley et al. (2012) studied how sketches, CAD models, and physical prototypes work effectively as boundary objects to negotiate about function and geometry. This paper elaborates on those studies but further investigates whether and how models support the negotiation of more downstream lifecycle aspects such as manufacturability and serviceability (Cavalieri \& Pezzotta, 2012), which often necessitate the raising of importance of non-functional properties in 
early design (e.g., repeatability in manufacturing and changeability; Worinkeng et al., 2015). Furthermore, this paper takes into account that models evolve during design phases resulting in increased levels of maturity and detail at each step of the process (Bertoni et al., 2016). In the early stages, models are predominantly linguistic or pictorial (e.g., requirement lists or decision trees), but virtual, algorithmic, or physical approaches are available in later stages (e.g., detailed CAD models, Finite Element Models and physical prototypes; Chandrasegaran et al., 2013).

\section{$3 \quad$ Research method}

An empirical study was undertaken to investigate the issue of negotiation supported by models in multidisciplinary design. The study was undertaken in collaboration with two Swedish construction equipment companies. One company develops earth-moving heavy equipment, such as excavators and wheel loaders, while the other company develops machines for road compaction and paving, such as asphalt compactors. Both companies also provide bundled product-service offerings, which draw attention to more downstream lifecycle properties in the early design phase of the machine hardware.

This research relied on 20 semi-structured interviews with questions being modified or added as the dialogue proceeded, based on the roles of the respondents (Robson, 2002). The key figures to be interviewed were selected with the support of two managers responsible for product development process improvement inside the two organisations acting as gatekeepers (Neyland, 2008). These managers were asked to identify experts belonging to different disciplines that are normally involved in decision gate meetings during development projects. The disciplines involved in this study were project management, marketing and sales, engineering design, procurement, manufacturing, 
and service. This selection, while limiting the range of trade-off negotiations that can be analysed, allowed the focus to remain on how practitioners use models to make the case for a particular design goal (in particular for those working with downstream issues such as procurement, manufacturing, and service).

Relying solely on interviews can limit the completeness of the dataset. A more complete dataset may be obtained by observing model use in the design process with observations and ethnography methods. Observation is certainly a powerful and reliable method but is extremely demanding of research resources when decision processes span a long time period (Mintzberg et al., 1976). For example, the anecdote reported in Excerpt B below spans approximately three months, while the one reported in Excerpt $\mathrm{C}$ spans one year (as reported by informants). Therefore, researchers were obliged to rely heavily on interviews.

Furthermore, tapping the memories of decision-makers can introduce errors of memory failure, as well as a risk of 'recall vs. reality' where people often overly rationalise their own viewpoints. The researchers approached these limitations by asking the interviewees beforehand to relate as much as possible of their last completed project so that these situations remained fresh in their minds.

\subsection{Data collection}

The interviews kicked-off by asking participants to describe the design task they are responsible for achieving as well as to name models and representations they use in their daily practice. Table 1 summarises this data and highlights how practitioners use models that are closely related to their tasks. For example, the procurement manager uses a release plan together with a bill of materials (in the form of spreadsheets) to ensure that the product will be released according to the required lead time and that it 
will meet cost reduction targets. Meanwhile, the service manager uses a service analysis

protocol to assess the serviceability of the design by giving qualitative scores for machine accessibility during service, as well as the probability of the service operation occurring during the machine's lifetime. The use of these different models to achieve different design tasks has an impact on the trade-off negotiation process and is, therefore, interesting for this study. At the same time, these models were used in different phases of the development project, further impacting the negotiation process.

Table 1. Key roles, design tasks and models used for the interviews

\begin{tabular}{|c|c|c|}
\hline Role & Design tasks and objectives & Models used \\
\hline Project Management & $\begin{array}{l}\text { Project managers are responsible } \\
\text { for monitoring project design and } \\
\text { reporting important decisions to } \\
\text { top managers. They ensure that } \\
\text { design requirements are met and } \\
\text { that development activities are } \\
\text { conducted within the established } \\
\text { timeframe and budget. }\end{array}$ & $\begin{array}{l}\text { During concept selection, they } \\
\text { organise sessions with the design team } \\
\text { where concepts are selected by using } \\
\text { matrix-based methods, such as Pugh. } \\
\text { The matrix is used by the entire team, } \\
\text { but the project manager is the owner } \\
\text { of the process. If important decisions } \\
\text { have to be reported to top } \\
\text { management, project managers } \\
\text { perform pay-off calculations using } \\
\text { spreadsheets, where simulations are } \\
\text { run (for example varying price } \\
\text { margins and production volumes). }\end{array}$ \\
\hline Marketing and Sales & $\begin{array}{l}\text { Their main role is to interview } \\
\text { operators and customers about the } \\
\text { key value-related aspects of a } \\
\text { machine. They provide input } \\
\text { about new machine requirements } \\
\text { and features. They are responsible } \\
\text { for providing feedback to } \\
\text { engineers about more intangible } \\
\text { aspects, such as visibility and } \\
\text { comfort. They are also } \\
\text { responsible for the increase in the } \\
\text { sale of service contracts and } \\
\text { financial programmes connected } \\
\text { to the machine. }\end{array}$ & $\begin{array}{l}\text { At the beginning of the project, } \\
\text { members of this department share a } \\
\text { list of rank-weighted needs based on } \\
\text { interviews with operators and } \\
\text { customers. They also draft a list of } \\
\text { system requirements together with the } \\
\text { design team. Here, matrix-based } \\
\text { methods, such as Quality Function } \\
\text { Deployment QFD, are often used. The } \\
\text { entire team uses the QFD matrix, but } \\
\text { the marketing and sales manager is the } \\
\text { 'owner' and initiator of the process. } \\
\text { These managers also use a Total Cost } \\
\text { of Ownership (TCO) tool, based on } \\
\text { machines already sold. This tool } \\
\text { provides an indication of the total } \\
\text { lifecycle costs for customers. } \\
\text { Comparisons to past machines in } \\
\text { terms of TCO are shared to provide an } \\
\text { indication of possible areas for TCO } \\
\text { reduction. This model is also used for } \\
\text { negotiations with customers during } \\
\text { sales. }\end{array}$ \\
\hline Engineering Design & $\begin{array}{l}\text { This department is responsible for } \\
\text { the engineering design of the }\end{array}$ & $\begin{array}{l}\text { In earlier stages, } 2 \mathrm{D} \text { models (e.g., } \\
\text { lumped mass models) are created, }\end{array}$ \\
\hline
\end{tabular}




\begin{tabular}{|c|c|c|}
\hline & $\begin{array}{l}\text { product from system } \\
\text { requirements until production. } \\
\text { They normally work within } \\
\text { subgroups, each responsible for } \\
\text { the design of a single subsystem. } \\
\text { They are also concerned about } \\
\text { meeting new environmental and } \\
\text { safety regulations. }\end{array}$ & $\begin{array}{l}\text { evolving to Finite Element Models } \\
\text { (FEM) once CAD models are created. } \\
\text { CAD models represent the main } \\
\text { objects of work for engineers. } \\
\text { Wireframe models are also created to } \\
\text { ensure visibility during asphalt } \\
\text { compaction. With time, physics-based } \\
\text { models for performance analysis are } \\
\text { created and simulated. }\end{array}$ \\
\hline Procurement & $\begin{array}{l}\text { One of the responsibilities of the } \\
\text { procurement manager is to ensure } \\
\text { that the product will be released } \\
\text { according to the required lead } \\
\text { time and that the machine } \\
\text { achieves the product cost } \\
\text { reduction requirement established } \\
\text { at the beginning of the project. }\end{array}$ & $\begin{array}{l}\text { The procurement manager uses a } \\
\text { release plan together with a bill of } \\
\text { materials (in the form of spreadsheets) } \\
\text { to compare alternatives (in terms of } \\
\text { lead time and costs) and to negotiate } \\
\text { with suppliers. These spreadsheets } \\
\text { evolve during the design project from } \\
\text { the description of a few generic } \\
\text { subsystem modules to a long bill of } \\
\text { materials (up to } 700 \text { parts). }\end{array}$ \\
\hline Manufacturing & $\begin{array}{l}\text { This department is responsible for } \\
\text { ensuring that the new design can } \\
\text { be manufactured and assembled } \\
\text { with minimal impact on the } \\
\text { existing production line in terms } \\
\text { of investments, resource } \\
\text { efficiency, and the working } \\
\text { environment for labourers. }\end{array}$ & $\begin{array}{l}\text { In the early phases, members of this } \\
\text { department review drawings and CAD } \\
\text { models released by engineering on a } \\
\text { product data management system, to } \\
\text { measure dimensions and estimate } \\
\text { production and assembly times. When } \\
\text { the final product is released, the bill of } \\
\text { materials is used to prepare production } \\
\text { operations. A simulation tool (based } \\
\text { on discrete-event simulation) is used } \\
\text { to optimise and balance the production } \\
\text { line (e.g., eliminating queues and } \\
\text { planning buffers). }\end{array}$ \\
\hline Service & $\begin{array}{l}\text { Managers from this department } \\
\text { must ensure that the machine } \\
\text { provides easy serviceability. If } \\
\text { easy serviceability is not possible } \\
\text { to be achieved (due to other } \\
\text { reasons), their role is to suggest } \\
\text { increasing the lifetime of } \\
\text { components. } \\
\text { They also provide input to } \\
\text { designers about intangible } \\
\text { objectives (such as comfort), } \\
\text { since they are in constant contact } \\
\text { with customers. }\end{array}$ & $\begin{array}{l}\text { At the beginning of the project, these } \\
\text { managers share statistical data about } \\
\text { spare parts claims and reparation } \\
\text { times from previous machines. Once } \\
\text { CAD models for product concepts are } \\
\text { released, service performs qualitative } \\
\text { analyses following a serviceability } \\
\text { assessment protocol. In later stages, } \\
\text { they perform ergonomic assessments } \\
\text { during service operations through the } \\
\text { use of human-machine simulation } \\
\text { software (which requires a detailed } \\
\text { CAD model). }\end{array}$ \\
\hline
\end{tabular}

In addition to the questions related to the design task and the models used, the researchers asked the participants to report past examples of cross-functional trade-offs (defined as a design conflict with at least one other discipline; Iorio \& Taylor, 2014). Interviewees were specifically asked about trade-offs that occurred in both late (towards the end of the development project and close to pre-production) as well as 
early design stages (product planning or conceptual design). This distinction was made under the assumption that models in design evolve during the process, and that this different level of maturity has an impact on the negotiation process. Afterwards, the questions directed the attention about the models brought up by the different participants involved in the trade-off situation. The researchers then asked what members did to solve the trade-off and asked the reasons why negative consequences (i.e., design reworks) eventually occurred.

\subsection{Data analysis}

The analysis of the recorded interview transcripts was conducted using a coding scheme (Strauss \& Corbin, 1990). This study used a mixed deductive-inductive coding approach (Miles et al., 2013, Saldaña, 2015). A provisional list of codes was created based on the key variables of interest. Additional codes were added as the coding activity proceeded. Table 2 displays the start list of codes used in this study. First, the interview material was coded according to how the use of models impacted the efficacy of the trade-off negotiation process (labelled EFF). Efficacy was coded following Iorio \& Taylor (2014), who propose the evaluation of whether and how the reference to a model impacts first 1) how early trade-offs are identified (duration of trade-off identification phase, EFF-ID) and 2) the duration of the trade-off resolution phase (EFF-RES). After coding the impact of models on negotiation efficacy, the researchers categorised the transcripts depending on whether the reference to models was made during the early or the late development phases (TIME-E or TIME-L). The type of model used was also coded (TYPE-M). Models mentioned by multiple interviewees were additionally coded as TYPE-BO, highlighting that the model may represent an instance of a boundary object (BO) as suggested by Bharosa et al. (2012). With such operationalization, the study highlighted boundary objects that appeared in different 
trade-off situations. Cross-analysing how the reference to models in early or late design impacted negotiation efficacy permitted the investigation of characteristics that limit the ability to use models as support for early design negotiation. First, the lifecycle aspects (ASP) involved in the trade-off situations were coded, based on the assumption that the type of aspect involved had an influence on the ability to use models as boundary objects. Initially, three main categories of aspects were distinguished: functional requirements, unit costs, and non-functional requirements. During the coding activity, the importance given to the aspects involved in the trade-off situation was qualitatively coded according to a scale (low, medium, high). Importance was coded in relative terms depending on the extent to which a lifecycle aspect was considered more or less important compared to another. For example, in Excerpt A in (section 4.1), a procurement manager reported how the engineering design department proposed a design for a sealing cap due to functional reasons. The excerpt continues describing how the design was changed later in the process, due to its high complexity. Since importance is coded in relative terms, the researchers assigned higher importance to 'functionality' compared to 'complexity' for the first episode of the excerpt (point A in figure 1). In the second episode (point B in figure 1), the researchers assigned higher importance to 'complexity' compared to 'functionality', since the design was changed in favour of complexity.

This coding activity highlighted how models possess certain characteristics that promote or constrain their use as boundary objects. The characteristics of boundary objects (CHA) which supported or constrained the negotiation process were initially coded based on definitions identified in the literature. The definitions and references used are described in Table 2. 
Table 2. The start list of codes used in the study.

\begin{tabular}{|c|c|c|}
\hline Category & Abbreviation & Description \\
\hline $\begin{array}{l}\text { Efficacy of trade- } \\
\text { off negotiation } \\
\text { process }\end{array}$ & EFF & $\begin{array}{l}\text { Efficacy is coded following Iorio \& Taylor (2014), and } \\
\text { divided in 'efficacy of trade-off identification' and 'efficacy } \\
\text { of trade-off resolution'. }\end{array}$ \\
\hline $\begin{array}{l}\text { Efficacy of trade- } \\
\text { off identification }\end{array}$ & EFF-ID & $\begin{array}{l}\text { Describes the impact on the duration of trade-off } \\
\text { identification (i.e., how early in the design process trade-offs } \\
\text { are identified), caused by a reference to a model during the } \\
\text { negotiation process. }\end{array}$ \\
\hline $\begin{array}{l}\text { Efficacy of trade- } \\
\text { off resolution }\end{array}$ & EFF-RES & $\begin{array}{l}\text { Describes the impact on the duration of trade-off resolution, } \\
\text { caused by a reference to a model during the negotiation } \\
\text { process. }\end{array}$ \\
\hline $\begin{array}{l}\text { Time of reference } \\
\text { to models (early or } \\
\text { late design) }\end{array}$ & $\begin{array}{l}\text { TIME } \\
\text { (TIME-E or } \\
\text { TIME-L) }\end{array}$ & Self-assessed by respondents. \\
\hline Type of model & $\begin{array}{l}\text { TYPE-M } \\
\text { (TYPE -BO) }\end{array}$ & $\begin{array}{l}\text { As reported by the respondents. All the models mentioned } \\
\text { were coded as TYPE-M. Models mentioned by multiple } \\
\text { interviewees were additionally coded as TYPE-BO, } \\
\text { highlighting that the model is an instance of a boundary } \\
\text { object (Bharosa et al., 2012). }\end{array}$ \\
\hline $\begin{array}{l}\text { Lifecycle aspect } \\
\text { involved in the } \\
\text { trade-off situation } \\
\text { (together with } \\
\text { given importance) }\end{array}$ & ASP & $\begin{array}{l}\text { A provisional list of aspects was created based on the key } \\
\text { variables of interest (deductive coding approach). } \\
\text { During the coding activity, the importance given to the } \\
\text { aspects involved in the trade-off situation was qualitatively } \\
\text { coded according to a scale (low, medium, high). }\end{array}$ \\
\hline $\begin{array}{l}\text { Functional } \\
\text { requirements }\end{array}$ & ASP-FR & $\begin{array}{l}\text { A functional requirement specifies "a function that a system } \\
\text { must be able to perform," "what the product must do," and } \\
\text { "what the system should do" (Shankar et al., 2010). } \\
\text { Functional requirements specify the inputs (stimuli) to the } \\
\text { system, the outputs (responses) from the system, and } \\
\text { behavioural relationships between them (Pahl \& Beitz, 2013). }\end{array}$ \\
\hline Unit cost & ASP-UC & $\begin{array}{l}\text { The unit cost is the cost incurred by a company to produce, } \\
\text { store and sell one unit of a particular product. }\end{array}$ \\
\hline $\begin{array}{l}\text { Non-functional } \\
\text { requirements }\end{array}$ & ASP-NFR & $\begin{array}{l}\text { Non-functional requirements constrain "how" the system } \\
\text { must accomplish the "what." Non-functional requirements } \\
\text { state constraints to the system as well as qualities a system } \\
\text { might have such as security, safety, usability, flexibility, or } \\
\text { customizability (Worinkeng et al., 2015). They are often } \\
\text { referred to as "-ilities" (e.g., maintainability and reliability) or } \\
\text { "-ities" (e.g., integrity and security). The non-functional } \\
\text { requirements restrict the types of solutions one might } \\
\text { consider (Ebert, 1997). }\end{array}$ \\
\hline $\begin{array}{l}\text { Characteristic of a } \\
\text { boundary object }\end{array}$ & CHA & $\begin{array}{l}\text { A quality or feature characterising a model to support the } \\
\text { trade-off negotiation activity. A provisional list was created } \\
\text { based on the key characteristics of boundary objects } \\
\text { identified in the literature. } \\
\text { During the coding activity, an additional code (CHA - LIM) } \\
\text { was added, indicating a limiting attribute that restricts the use } \\
\text { of the boundary object in early-design. }\end{array}$ \\
\hline $\begin{array}{l}\text { Boundary objects } \\
\text { in time }\end{array}$ & CHA - TIME & $\begin{array}{l}\text { Describes the degree to which the mentioned boundary object } \\
\text { can actively be manipulated by the various participants during } \\
\text { the design process (Boujut and Blanco, 2003), especially by } \\
\text { those who work in the downstream activities (manufacturing } \\
\text { or service). As a consequence, the mentioned boundary object } \\
\text { connects one design effort to the next, serving as a boundary } \\
\text { object in time (Boujut \& Laureillard, 2002). }\end{array}$ \\
\hline
\end{tabular}




\begin{tabular}{|l|l|l|}
\hline $\begin{array}{l}\text { Manage } \\
\text { complexity }\end{array}$ & CHA - CO & $\begin{array}{l}\text { Describes the degree to which the mentioned boundary object } \\
\text { manages complexity by reducing the instantaneous cognitive } \\
\text { load during decision-making (Richards et al., 2007). }\end{array}$ \\
\hline Applicability & CHA - APP & $\begin{array}{l}\text { Describes the degree to which the mentioned boundary object } \\
\text { can be applicable to different trade-off situations. This } \\
\text { definition is closely connected to the definition of boundary } \\
\text { objects provided by Eckert et al. (2001): 'Objects that can be } \\
\text { read differently by people with different concerns and } \\
\text { expertise'. }\end{array}$ \\
\hline
\end{tabular}

The analysis of internal company documentation and debriefing activities, in the form of regular virtual and physical meetings, was used for triangulation purposes.

\section{Results}

The fieldwork presented below will draw particular attention to the ways that downstream issues come into play in the design process, and the ways that models do or do not facilitate this.

\subsection{The challenge of negotiating through models in design: late vs. early design}

The first set of data is a series of three excerpts that depicts how practitioners use established model-based means to make the case for a particular design goal. These excerpts provide the reader with a set of comparisons for the use of models to identify and resolve trade-offs, distinguishing between late and early stages of development projects.

\section{Excerpt A - Negotiation between functionality and geometrical complexity}

This excerpt, provided by a procurement manager, is related to a design situation occured in the late development stages of an asphalt compactor. The product to be designed was a sealing cap, which is a part used to seal the engine compartment. The whole anecdote behind the excerpt is visualized in Figure 1. It positions the different moments involved in the negotiation process (points A and B) on the project timeline. The lifecycle aspects involved in the trade-off are also visualized, together with the 
importance given at that specific moment in time. During the coding activity, the importance was qualitatively coded according to a scale (low, medium, high). Importance was coded in relative terms depending on the extent to which a lifecycle aspect was considered more or less important compared to another.

The focal point of this excerpt is the use of a boundary object (CAD model) to transform the current design in the late stages after mutual concerns between procurement and engineering are expressed:

'When I saw this CAD drawing [author's note: the respondent is pointing at the drawing], I said that this will be complex and expensive [...], and as we usually have very simple solutions, it was based on my own experience. They designed this because they had to solve the function; the function was to seal so that the engine compartment could remain cold [...]. I do not know their stuff, but when I saw this model, I thought they could solve that function with a cheaper solution.'

This excerpt provides a glimpse into how the procurement manager identified a tradeoff between the complexity of the CAD geometry (proposed by the engineering department for functional reasons) and translated this complexity into her area of expertise ('complex and expensive') of procurement.

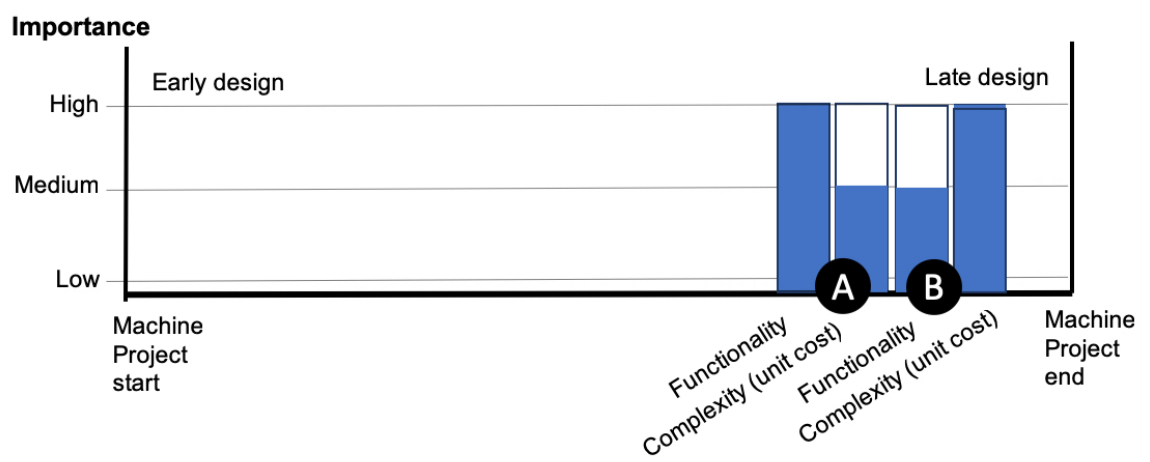
A Engineering proposes a design for the sealing cap (through CAD)
B Procurement uses the CAD model to identify and resolve the trade-off with engineering

Figure 1. Sealing cap design. 
The excerpt highlights how the CAD model functioned as a fundamental support for the procurement manager to identify this trade-off ('when I saw this CAD drawing'), even though she did not take part in the engineering creation of the geometry and its underlying rationale ('I do not know their stuff'). Sketches, computer drawings, and physical prototypes are key boundary objects, because their flexibility makes them interpretable differently by people with different concerns and expertise (Henderson, 1991). This excerpt highlights how the availability of such boundary object facilitates joint trade-off identification and resolution between the functional and geometrical properties of a design.

\section{Excerpt B - Negotiation among structural robustness, unit cost, and serviceability}

This excerpt introduces the challenges for individuals working within downstream disciplines - manufacturing or service - to engage in early design due to a lack of objects that are shareable across different problem-solving contexts. In particular, this excerpt introduces the difficulty to trade with non-functional objectives (e.g., serviceability) in early design, due to the lack of objects supporting such negotiation process.

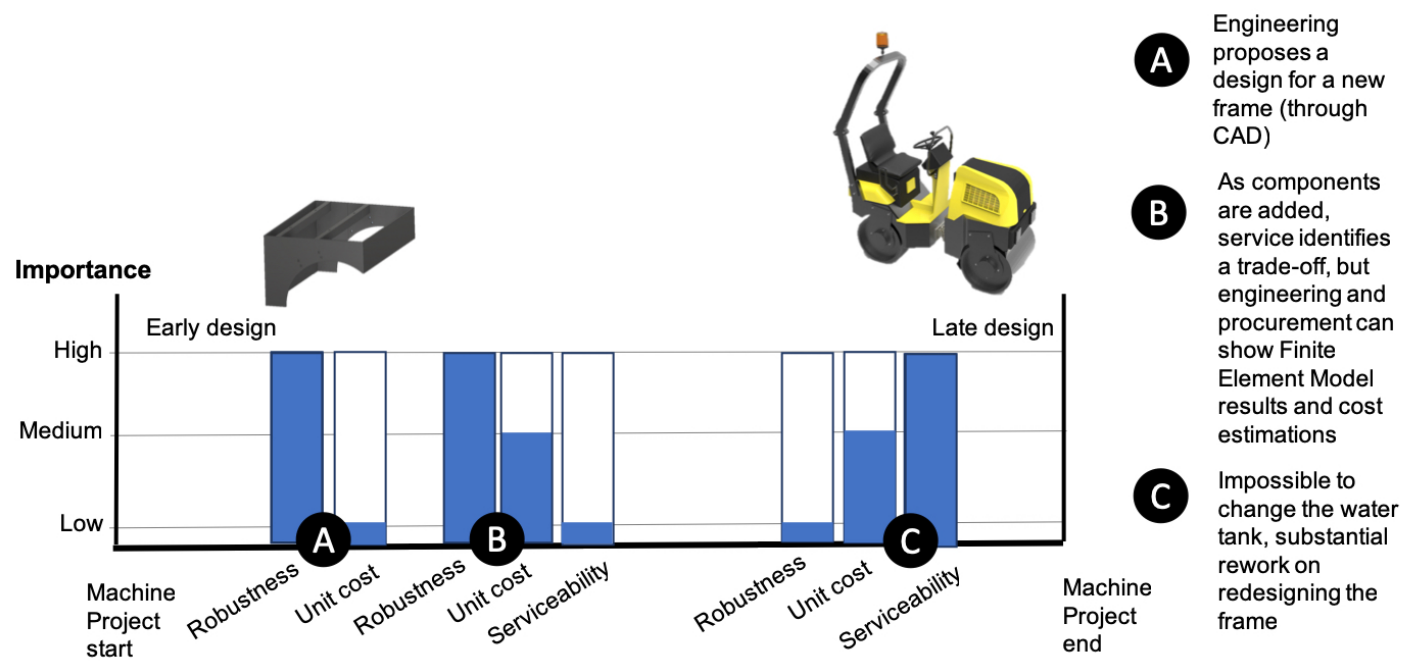

Figure 2. Frame design. 
In the conceptual stage of the design of a new asphalt compactor, the engineering manager presented a novel concept for the machine frame using CAD models, that was characterised by a less complex topology with straighter steel beams (point A in Figure 2). To demonstrate the positive impact of this novel concept on overall robustness, the engineering manager presented the results of FEM simulations. During meetings, this concept proposal was appraised by the procurement manager, who presented early estimations of how this concept contributed substantially to meeting the ambitious cost reduction target established at the beginning of the project (point B in Figure 2). As the project advanced, new concepts for the components were designed and added. In particular, a concept for a larger water tank was added, to increase the ability of customers to operate the machine without stops. At this point, the service manager realised that the frame shape would make it difficult to repair or replace the larger water tank during service (point $\mathrm{C}$ in Figure 2). When asked about the reason why this discovery happened late in the project, the manager replied as follows:

'Earlier in the project, I usually present statistical data from previous machines regarding spare parts claims and reparation times to demonstrate what needs to be improved, but this was a new concept for the frame.'

A substantial amount of time was spent in redesigning the frame of the asphalt compactor. This story illustrates that while the CAD model, results from FEM, and the unit cost estimation represented the concerns of engineering and procurement, design activity resulted in late discovery of a problem with the frame. This arose because the service manager was unable to identify the trade-offs through the CAD, FEM, and unit cost models of the frame. The new frame design introduced a source of novelty (Carlile, 2002) for the downstream function (e.g., service), which prevented the effective 
recognition of trade-offs and dependencies. Such models were therefore closed (Boujut \& Blanco, 2003) to the service manager. Earlier representations (e.g., repositories of spare parts and reparation times) were not up to date (because both the frame and the water tank were new concepts). Because these repositories were not up to date, they failed to represent the service manager's concerns, and thus the trade-off was not identified until the design reached a more advanced stage in the project.

\section{Excerpt C - Negotiation about visibility and precision in operation}

This excerpt is an anecdote that describes how engineers in early design find it difficult to build common ground when making the case for non-functional objectives (Worinkeng et al., 2015) such as visibility and precision of operation.

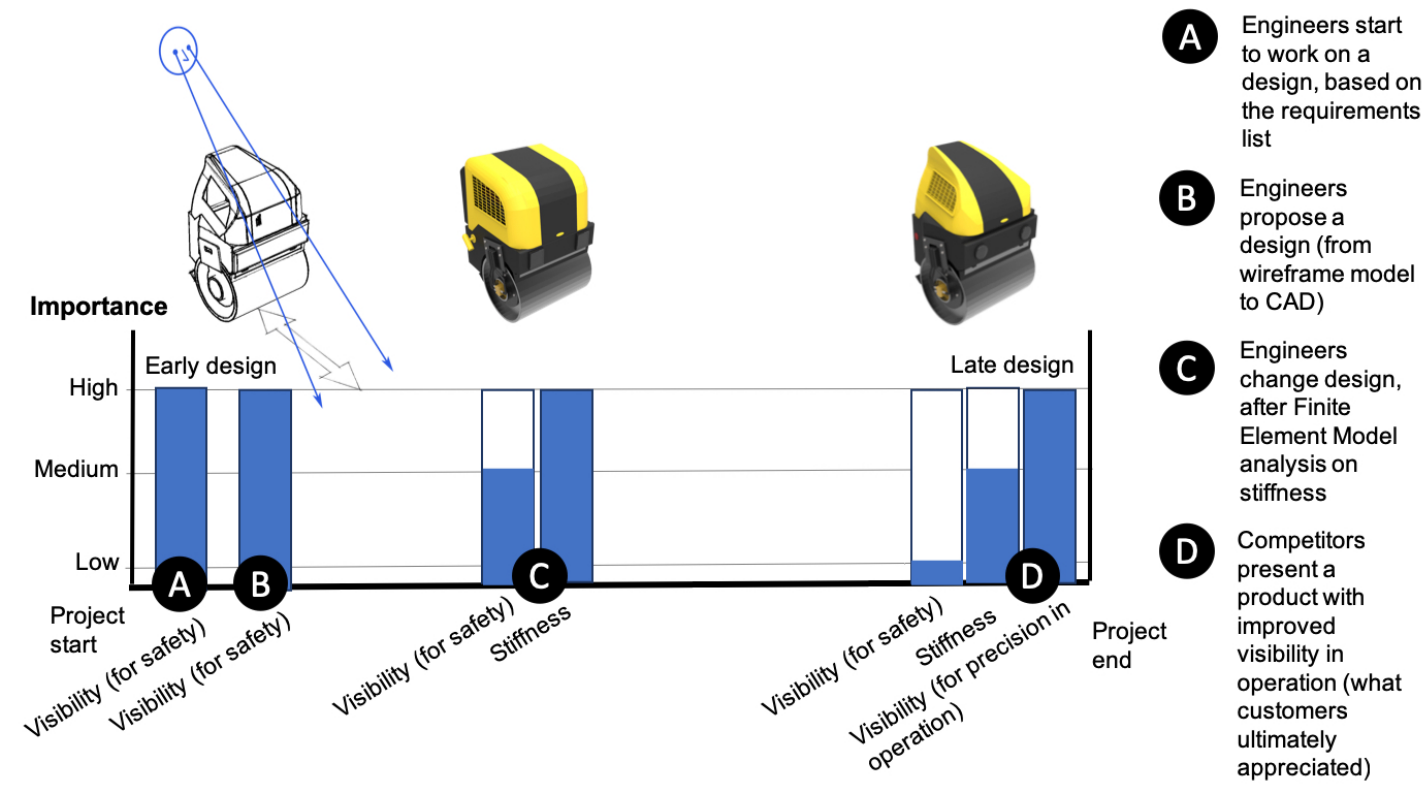

Figure 3. Engine hood design.

At the beginning of a project, an engineering manager worked together with marketing to propose a new design for the engine hood (Figure 3). A requirement captured in the requirements list was to be compliant with the new visibility regulations for operator safety reasons. The engineer started to work on a new design using a wireframe model 
(point $\mathrm{B}$ in Figure 3), further refining it as a CAD model after ensuring with marketing that the requirement on the list was met. As the project advanced and the CAD model was analysed by a structural engineer (through FEM), it was decided to slightly change the shape of the engine hood in order to insert stiffeners (point $\mathrm{C}$ in Figure 3). To make sure that the visibility requirements were met with the new geometry, engineers made use of the requirements list together with marketing. However, when the machine was released to the market, the design team realised that a competitor's new machine featured a geometry of the engine hood with improved visibility that both outperformed the regulation requirement and allowed more precise operation (point D in Figure 3). As a reflection, the engineering manager pointed out the following:

'the market and sales department is the one who sets the target requirements, and we find it difficult to prove against the list of requirements'

This excerpt is interesting because it illustrates how the issue of 'improving visibility for precision in operation' was never identified during the whole project (point D in Figure 3). The negotiation process never started. For this engineer it was difficult to identify this issue earlier in the process and to claim for a better design that outperformed the target requirements (captured in the requirements list) with the available wireframe and CAD models.

\subsection{Boundary objects supporting and constraining negotiations during trade- off identification: CAD models and simulation results}

The three excerpts above highlighted how downstream lifecycle issues run the risk of being neglected (or down-prioritised) during early design trade-offs, because of the characteristics of the models that are used. This section will analyse these characteristics at a deeper level, distinguishing between models supporting trade-off 
identification and trade-off resolution. Firstly, this section will focus on two types of boundary objects (CAD models and simulation results) that were mentioned by multiple interviewees as key models being involved in trade-off identification. This section will use three excerpts from the empirical material to highlight how such models - which worked as a boundary object in one setting - can become a boundary roadblock when taken to another setting. The section will highlight:

- how the use of CAD models constrains the ability to negotiate between functional and non-functional aspects of a design, and

- how the use of simulation results as boundary objects is constrained by the rigidity in information exchange between modelling domains.

\section{Excerpt D - CAD models constrain negotiations between functional and non- functional aspects of a design}

Excerpt A (sealing cap) already highlighted how CAD models represent key means to identify trade-offs between functional and geometrical properties of a design. However, Excerpt $\mathrm{C}$ (engine hood design) described how engineers in early design find it difficult to use CAD models to build common ground about non-functional objectives, such as visibility and precision of operation. This ability is even more constrained for participants working with downstream disciplines, as one engineer reflected:

'In general, the engineering department has great power because we sit with the design, we sit with the 3D model, and we are able to say what can or cannot be designed, and it is difficult for all [author's note: the members of the other disciplines] to prove against if it is not quite obvious.' 
While it is relatively intuitive to relate the geometrical complexity of a CAD model to the unit cost of the part, it is more difficult to relate how such a choice would impact aspects such as brand, flexibility, serviceability, and production line commonality. For instance, marketing or service managers do not have complete technical insights into how these detailed engineering properties impact such aspects of their domain. Conversely, engineers do not often have full insight into how these technical characteristics will impact the needs and expectations of the marketing and service departments. This means that downstream lifecycle issues come into play in a later stage of the design process. As a manufacturing manager reported 'most often I find $90 \%$ of the trade-offs after building the prototype'. This is because CAD models present a limited ability to be actively manipulated by the various participants involved in tradeoff identification, especially by those who work in the downstream activities (manufacturing or service).

\section{Excerpt $E$ and $F$ - The use of simulation results is constrained by the rigidity in information exchange between modelling domains}

To identify the impact of a design concept on diverse lifecycle aspects, participants make extensive use of simulations and experimentations with models. Table 1 illustrates how almost all the disciplines involved in the study adopted some simulation software to perform part of their design tasks. Marketing and sales managers used a TCO simulation tool to identify areas for cost reduction improvement based on machines previously sold on the market. Engineers made extensive use of FEM for structural analysis, while the service department adopted human-machine simulation software to perform ergonomic analysis during service (after a detailed CAD model was available). Executing models through simulations and experimental design is a powerful method to rapidly screen influential design variables. It is important that 
models are executable so as to support trade-off identification by means of experimentation.

However, not all the disciplines possess the same ability to use simulations at the same point in time. This depends on the poor flexibility in exchanging information between modelling domains, making models too inflexible to be managed in a continuous workflow. This closes simulations to multidisciplinary negotiation because they poorly connect one design effort to the next (Boujut \& Laureillard, 2002). This limitation has much in common with the insight provided in Excerpt B (indicated as point B in Figure 2). The service manager could not use the software for serviceability assessment in early design to understand the implications of the frame design on his own domain. The manager pointed out the following:

'It's difficult when you do not really know how the components will be placed inside the frame [...]. Sometimes during the project, you make new trade-offs, so the components are moving around in the machine all the time during development. It's usually towards the end when you first see trade-offs [...].'

While engineering and procurement could make their analyses with simulation based only on the frame design (point B in Figure 2), service needed to wait for the input about the whole system to be able to run a serviceability simulation. It is difficult to release this information at an earlier stage of the development process ('the components are moving around in the machine all the time') because of constrained flexibility.

To provide another example, the following excerpt illustrates how manufacturing finds it difficult to use production simulations to identify trade-offs at earlier stages: 
'We use a simulation tool to balance the line [...], but you can use it when the machine design is quite frozen [...]. If you want to use it before, there's a risk that we have to redo everything because the design has changed.'

Therefore, the lack of awareness about the end-game solution (constrained by the rigidity in information exchange across modelling domains) hinders downstream representatives in identifying trade-offs. This makes it difficult for some decisionmakers to be aware of how decisions made by upstream functions (e.g., engineering design) influence their tasks.

\subsection{Boundary objects supporting and constraining negotiations during trade- off resolution: Total Cost of Ownership and decision matrices}

Interview results indicate that resolving trade-offs is predominantly a matter of agreeing on a shared definition of lifecycle 'merit' or 'goodness' for the product to be developed. This issue is particularly important in situations where design proposals increase the investment cost of the product but provide benefits in the longer term. The analysis of the interview transcripts illustrates how trade-offs happen at the interfaces between different stakeholders:

- among the multidisciplinary design team;

- with top managers,

- $\quad$ with customers, and

- with suppliers,

At these interfaces, it is important to effectively provide arguments that shift the balance of power (Goodwin, 1993). In this context, models play a powerful bargaining role, both in a positive as well as in a negative way. As a manufacturing manager pointed 
out 'the most difficult in earlier steps is just to explain why manufacturing cannot perform a certain operation on the production line. It's important to be able to convince the others and to have enough supporting facts so that we can go on my line of thoughts. It's really a matter of selling an argument, simply'. This is very important for practitioners working with downstream functions, who often struggle to emphasise longer-term benefits (e.g., manufacturability, serviceability, and upgradability). One service manager reported the following: "today the focus is very much on cost. It has to be cheaper, so it's really difficult to get through something that makes the machine more expensive-even if it can generate or save money in the long run. Top management wants the machine $15 \%$ cheaper, so one struggles to make it as easy and cheap as possible, but then I come in with other things that I would like to be optimal, and then there will be trade-offs."

This section will analyse two types of boundary objects (Total Cost of Ownership or TCO, and decision matrices) which were mentioned to be involved in trade-off resolution. This section will use four excerpts to highlight the characteristics that promote or limit the use of boundary objects in early design. The section will highlight:

- how the use of TCO as a boundary object is constrained by the rigidity in information exchange between modelling domains,

- how the use of TCO as a boundary object is constrained by the unclear communication of how 'mature' the models populating a TCO equation should be, and

- how the use of decision matrices as boundary objects is constrained by the limited ability to represent non-linear relationships. 


\section{Excerpt $\mathrm{G}$ - the use of TCO as boundary object is constrained by the rigidity in information exchange between modelling domains}

To resolve critical trade-offs, the respondents often engage in cost-benefit calculations based on monetary terms. In the studied companies, respondents highlighted how TCO represents a convenient and practical metric that is commonly understood and shared by the stakeholders, representing a common boundary. As a project manager pointed out:

'the most difficult trade-offs are when the technology improvement increases the investment costs. Among these trade-offs, the easier ones to solve are when you can actually calculate what the cost is and what will be the benefit in terms of money'.

TCO is just one example of a monetary-based definition which targets the whole lifecycle. Such a monetary model can be populated differently by all stakeholders involved in the design negotiations (multidisciplinary design team, top managers, customers, and suppliers) while at the same time representing a common boundary to resolve tradeoffs. In the studied companies, using TCO is a convenient and practical metric to shift the balance of power and increase the importance of downstream lifecycle issues.

Although monetary-based definitions represent a shared boundary for effective tradeoff resolution, their population with models in early design stages presents difficulties. The rigidity in information exchange plays again a role in this context, making it difficult to connect one design model (e.g., CAD) to the next (e.g., a serviceability simulation tool) and to connect them together to a shared definition of lifecycle 'goodness', such as TCO. The resolution of the trade-off related to the water tank in Excerpt B (indicated as point B in Figure 2) provides a concrete example. Once the 
trade-off between robustness and serviceability was identified, the service manager attempted to convince the other group members about the negative consequence of the frame design. However, he did not succeed because the engineering department was able to demonstrate the positive impact of the frame on TCO, since procurement was able to show early calculations on the reduced investment cost of this design. These results met the approval of both the project manager and top management since the design represented a substantial contribution to total cost reduction. The service manager could not use the software for serviceability assessment in early design to populate 'his part' of TCO (e.g., replacement costs, service time) in order to shift the balance of power in the collective discussion with engineering, procurement, and the project lead.

The above-mentioned anecdote suggests that certain functional groups (engineering, project management, procurement) felt more comfortable than their counterpart (service) during the trade-off resolution stage because of what the models were able to represent (reduced investment cost and hence lower TCO). As a consequence, the service manager found it difficult to effectively provide arguments that shifted the balance of power towards serviceability-related aspects. This led to skewed equality in the balance of power between stakeholders.

\section{Excerpt $\mathrm{H}$ - the use of TCO as boundary object is constrained by the unclear communication of how 'mature' the models populating a TCO equation should be}

Models from upstream functions are in general more mature than models belonging to downstream functions (e.g., manufacturing or service) when compared at the same point in time. Downstream lifecycle models emphasise longer-term benefits (e.g., 
manufacturability, serviceability, and upgradability), even often gleaning into the use phases and beyond in the product's lifecycle and are hence less mature if used in the earlier stages. With different model quality and fidelity, it is a risk that decision-makers will approach a trade-off decision situation with skewed expectations, depending on how trustworthy a model may be. Trade-off resolutions are highly dependent on how well the members trust the models. There is a high risk that a difference in the trust will shift the balance of power no matter what the model results are. For example, a manufacturing manager reported a trade-off with procurement. The trade-off was related to the decision about:

1. keeping the current solution; having a single hose throughout the whole machine length (more expensive, but with no need for assembly on the production line), or

2. to have several hoses assembled in production.

In this case, the two parties developed models and calculated which alternative presented a lower total production cost (the sum of the unit cost to buy and the assembly cost). The 'several hoses option' presented a lower total production cost. Since it was a new solution, the assembly cost model developed by the manufacturing manager was based on a number of assumptions, while the unit cost to buy model developed by procurement was based on current price tags. When presenting to the whole team the results of these combined models (which indicated a preference for the several hoses option), the project lead asked the manufacturing manager to purchase the hoses and to perform a test with time measurements on the current assembly line. The manufacturing manager expressed some frustration with this: 
'it [atuhor's note: the test] basically confirmed what I had already calculated, but three weeks later'

This excerpt highlighted how the use of TCO as a boundary object is constrained by how trustworthy the models behind its calculation are. A major challenge is if decisionmakers feel confident to make a certain decision. Comparing two different models of incomparable fidelity means that the model that has lesser developed details and experience built up around it will run the risk of favouring negatively compared to the ones that have a legacy from previous projects (Johansson et al, 2017). As illustrated in this excerpt, more detailed information is obviously needed to satisfy decision-makers' confidence demands, but sometimes expectations for what that information should be, what question should be answered, and how, are undefined or poorly communicated beforehand, which means that the information produced might not motivate the decision. This excerpt highlighted how developing an assembly model (populating a TCO equation) ended up being no decision made, and with the manufacturing manager being reverted to try and find the 'right' information by other means than the models presented (time measurements on the assembly line). Participants expressed frustration with this, where they often would like to see that a decision is made - even if it is the "wrong" decision - because that keeps momentum. A wrong decision can be changed, but with no decision, there is also no action. One participant wondered rhetorically 'if they were doing too much physical measuring' for this reason. Waiting can be frustrating, and members may instead choose to make a potentially wrong decision that will at least maintain momentum and that can be amended further ahead in the process.

\section{Excerpt $\mathbf{I}$ and $\mathbf{J}$ - The use of decision matrices as boundary objects is constrained by the limited ability to represent non-linear relationships}


'It becomes a matter of daring to define them [author's note: relationships between design alternatives and stakeholders' needs], then you can always change these relationships. But if you have them defined it becomes easier to point at them. It is a matter of systematically doing it while you work, I think it is a big benefit'.

This excerpt, reported by a project manager, exemplifies the reasons why respondents use qualitative and matrix-based decision matrices (e.g., QFD or a Pugh matrix) to be proactive and to drive points home in communications with engineers (who will otherwise not automatically focus on these important targets). This is particularly relevant to identify and resolve trade-offs about non-functional objectives by making high-level assertions and assumptions explicit. Decision matrices contain elements of what Boujut \& Hisarciklilar (2012) define as 'semantic annotations'. Semantic annotations can be described as annotations that are interpretable (or reusable) by a human being in a given context. Semantic annotations possess some general properties, for example:

- they have a different nature from the document on which it is attached to (for example representing non-geometrical information on a geometrical CAD object).

- The anchor of an annotation is the point onto the document, where the annotation is attached.

The iconic and semantic nature of decision matrices makes them interpretable by a large number of design participants. Yet respondents highlighted how the use of decision matrices as boundary objects is constrained by the limited ability to represent non-linear relationships. For example, Excerpt $\mathrm{C}$ already highlighted how a slight change in the 
geometry of an engine hood had a large impact on the perceived benefit by the final customer. Such non-linearity can become a boundary roadblock for negotiations between functional and non-functional aspects of a design.

An engineer pointed out the following:

'to value a feature is tricky. It is difficult. Often it becomes very vague [...]. Everything cannot be expressed in figures, or it is really difficult.'

The predominance of non-linear relationships limits the ability to use decision matrices as boundary objects. QFD, for example, enables to use semantic annotations and correlation coefficients but does not allow to map non-linear relationships so that it does not allow to 'easier point at them'.

\section{Discussion: characteristics that promote or constrain the use of models as decision supports}

The results of this study provide a qualitative explanation about the role of models not only as a means to compute a set of input to produce a set of output (i.e., computational models) but also as supports to make decisions that are 'sufficiently agreeable' or 'good enough' through the development of shared meaning (Larsson, 2003). With this perspective, the analysis of the fieldwork highlighted how "downstream" lifecycle issues run the risk to be neglected (or down-prioritised) during early design trade-offs, because of the models different disciplines are (or are not) able to use at specific points in time. These findings contribute to the discussion about the role of models as ‘boundary objects' between identified stakeholders (Star \& Griesemer, 1989; Barley et al., 2012). Compared to previous studies, this paper highlighted how practitioners use different boundary objects in two distinct phases of the negotiation process (trade-off 
identification and trade-off resolution). In particular, interviewees used two key boundary objects for trade-off identification (CAD models and simulation results) and two key boundary objects for trade-off resolution (TCO and decision matrices). Despite the limited dataset, these results can provide insights about what factors should be taken into account when organizing and synthesizing models in novel decision-support systems.

First, the fact that different boundary objects were used during negotiations suggests that organizing a modular build-up of key boundary objects in a novel decision support system could achieve a more collective ownership of the design objectives and tradeoffs. There is currently a trend to develop such collaborative environments, for example the decision theatre at Arizona State University (White et al., 2015) and the decision arena at Blekinge Institute of Technology (Wall et al., 2018). Following this trend, the study highlighted the benefit of taking a boundary object perspective in the development of a decision support system. In addition, this study characteristics that promote or constrain the use of the four identified boundary objects during early design negotiations (CAD models, simulation results, Total Cost of Ownership and decision matrices). Table 3 summarizes this data, which can answer not only "what" influenced the negotiation process, but also "how" and "why". 
Table 3. Characteristics and consequences of key boundary objects.

\begin{tabular}{|c|c|c|c|c|c|}
\hline $\begin{array}{l}\text { Impact on } \\
\text { trade-off } \\
\text { negotiation }\end{array}$ & $\begin{array}{c}\text { Design } \\
\text { stage }\end{array}$ & $\begin{array}{c}\text { Key } \\
\text { Boundary } \\
\text { objects } \\
\text { identified }\end{array}$ & $\begin{array}{c}\text { Characteristics } \\
\text { promoting the } \\
\text { use as a } \\
\text { boundary } \\
\text { object }\end{array}$ & $\begin{array}{l}\text { Characteristics } \\
\text { limiting the use } \\
\text { as a boundary } \\
\text { object in early } \\
\text { design }\end{array}$ & Consequences \\
\hline \multirow[t]{2}{*}{$\begin{array}{l}\text { Trade-off } \\
\text { identification }\end{array}$} & $\begin{array}{l}\text { Early } \\
\text { design }\end{array}$ & $\begin{array}{l}\text { CAD } \\
\text { models }\end{array}$ & $\begin{array}{l}\text { CAD models can } \\
\text { be read } \\
\text { differently by } \\
\text { people with } \\
\text { different } \\
\text { concerns and } \\
\text { expertise (Eckert } \\
\text { et al., 2001). }\end{array}$ & $\begin{array}{l}\text { CAD models } \\
\text { become a } \\
\text { boundary } \\
\text { roadblock for } \\
\text { negotiations } \\
\text { between } \\
\text { functional and } \\
\text { non-functional } \\
\text { aspects of a } \\
\text { design. }\end{array}$ & $\begin{array}{l}\text { 'most often I } \\
\text { find } 90 \% \text { of the } \\
\text { trade-offs after } \\
\text { building the } \\
\text { prototype': } \\
\text { trade-offs with } \\
\text { non-functional } \\
\text { objectives come } \\
\text { into play in the } \\
\text { later stages of } \\
\text { the design } \\
\text { process. }\end{array}$ \\
\hline & $\begin{array}{l}\text { Early and } \\
\text { late } \\
\text { Design }\end{array}$ & $\begin{array}{l}\text { Simulation } \\
\text { results }\end{array}$ & $\begin{array}{l}\text { Simulation } \\
\text { results reduce the } \\
\text { instantaneous } \\
\text { cognitive load } \\
\text { because they } \\
\text { allow to rapidly } \\
\text { screen influential } \\
\text { design variables. }\end{array}$ & $\begin{array}{l}\text { The rigidity in } \\
\text { information } \\
\text { exchange between } \\
\text { modelling } \\
\text { domains. }\end{array}$ & $\begin{array}{l}\text { Difficult for } \\
\text { some decision- } \\
\text { makers to be } \\
\text { aware of how } \\
\text { decisions made } \\
\text { by upstream } \\
\text { functions } \\
\text { influence their } \\
\text { tasks. }\end{array}$ \\
\hline \multirow[t]{2}{*}{$\begin{array}{l}\text { Trade-off } \\
\text { resolution }\end{array}$} & $\begin{array}{l}\text { Late } \\
\text { Design }\end{array}$ & $\begin{array}{l}\text { Total Cost } \\
\text { of } \\
\text { Ownership } \\
\text { (or other } \\
\text { monetary } \\
\text { definitions } \\
\text { of lifecycle } \\
\text { worth) }\end{array}$ & $\begin{array}{l}\text { Monetary-based } \\
\text { definitions can be } \\
\text { populated } \\
\text { differently by } \\
\text { stakeholders } \\
\text { while at the same } \\
\text { time representing } \\
\text { a common } \\
\text { boundary. }\end{array}$ & $\begin{array}{l}\text { (1) The rigidity in } \\
\text { information } \\
\text { exchange between } \\
\text { modelling } \\
\text { domains and (2) } \\
\text { the unclear } \\
\text { communication of } \\
\text { how 'mature' the } \\
\text { models populating } \\
\text { a TCO equation } \\
\text { should be. }\end{array}$ & $\begin{array}{l}\text { (1) Skewed } \\
\text { equality in the } \\
\text { balance of } \\
\text { power between } \\
\text { stakeholders } \\
\text { (2) Limited } \\
\text { trust in the } \\
\text { models } \\
\text { populating a } \\
\text { TCO equation, } \\
\text { if used in earlier } \\
\text { design stages. }\end{array}$ \\
\hline & $\begin{array}{l}\text { Early } \\
\text { Design }\end{array}$ & $\begin{array}{l}\text { Decision } \\
\text { matrices }\end{array}$ & $\begin{array}{l}\text { The iconic and } \\
\text { semantic nature } \\
\text { of decision } \\
\text { matrices makes } \\
\text { them } \\
\text { interpretable by a } \\
\text { large number of } \\
\text { design } \\
\text { participants. }\end{array}$ & $\begin{array}{l}\text { Limited ability to } \\
\text { represent non- } \\
\text { linear } \\
\text { relationships, } \\
\text { especially } \\
\text { regarding impact } \\
\text { on non-functional } \\
\text { aspects. }\end{array}$ & $\begin{array}{l}\text { Skewed } \\
\text { equality in the } \\
\text { balance of } \\
\text { power between } \\
\text { stakeholders. }\end{array}$ \\
\hline
\end{tabular}

Cross-analysing Table 3 can provide further recommendations for the development of novel decision support systems:

1. CAD models support the identification of trade-offs, because they can be read differently by people with different concerns and expertise (Henderson, 1991; 
Perry and Sanderson, 1998; Barley et al., 2012). However, this study highlighted how CAD models present a limited ability to be actively manipulated by those professionals working in downstream activities (manufacturing or service). As a consequence, trade-offs between functional and non-functional objectives come into play later in the design process. To solve this problem, one opportunity is to extend the inclusion of semantic annotations in CAD models (Boujut \& Hisarciklilar, 2012) to include more nonfunctional objectives (flexibility, changeability, upgradability, brand image).

2. Simulation results support the identification of trade-offs, because they allow to reduce the cognitive load by the rapid screening of influential design variables. However, the rigidity in information exchange between modelling domains makes it difficult for some decision makers to use simulations during early design. This constrains the ability of these decision-makers to be aware of how decisions made by upstream functions influence their tasks. Such constraints ask for more flexible approaches to information exchange. Current research is focusing on novel approaches to automatic generation of flexible CAD models (Amadori et al. 2012). The results of this study point to need for extending such approaches to include flexible information exchange with models of manufacturing, service, and operation.

3. Improving the flexibility of information exchange can create a basis for monetary quantification earlier in the design process (e.g., populating a TCO equation). In this way, the TCO results (or other monetary definitions of lifecycle worth) could be used earlier in the process as supports for trade-off resolution, because they can be populated differently by different stakeholders and represent a common boundary. 
4. During trade-off resolution, the use of decision matrices plays a key role as a boundary object, because their iconic and semantic nature makes them interpretable by a large number of design participants. However, while nowadays most of the existing mapping approaches exploit linear relations (such as in the Quality Function Deployment), the dependencies between design objectives are often nonlinear. This suggests expanding QFD mathematics with concave and convex functions that better communicate the complexity of tradeoff activities.

5. The efficacy of trade-off resolution is also influenced by the degree to which the stakeholders trust the boundary objects used in the negotiation process. The empirical material point to the need to balance between different boundary objects, to negotiate about what is required for a model to be trusted and inform the decision to be made. One way to do this is to visualize the maturity of models in relation to their impact on the decision, for example through Model Maturity Levels (MML, Johansson et al., 2017). The visualization of a Model Maturity Level ahead of the decision gate can direct the design team to improve the maturity of the models that highly affect the end result (e.g., TCO), while under prioritizing the maturity of models with low impact on the end result. That way decision-makers and model-creators can have a "meta-model"-facilitated discussion about the information requirements for a certain decision, and thus also about the model that should inform the decision. Sometimes a preliminary indication is enough as an output, whereas other times - often later in the development lifecycle - more trustworthy information is needed, which means that higher-fidelity models needs to be developed to instill confidence for the decision-makers. 
The findings from this study point to the need to consider the social context of the design activity as a decisive factor for the development of a decision support system. With this perspective, each individual designer uses models to strive for a shared understanding with their colleagues to produce a successful design (Boujut \& Hisarciklilar, 2012).

\section{Conclusions}

The findings from this study point to the potential of using models to achieve a more collective ownership of objectives and trade-offs in early design. This is important for industry today, since the trend in 'digitalization' is driving the improvement of computational performances of models and simulations. While such improvements are important, this study still emphasized the role of models as collaboration facilitators through discussion and knowledge sharing (i.e., 'boundary objects'; Star \& Griesemer, 1989). This is particularly relevant for the early design phases, since not all information can be readily available through computational models. In such situations, effective decision-making still needs to rely on the ability of stakeholders to develop shared meaning through models.

This study highlighted the importance of taking a boundary object perspective in the development of a collaborative decision support system - for example organizing a modular build-up of key boundary objects. With this perspective, this study pointed to the improvement of four key boundary objects (CAD models, simulation results, TCO and decision matrices) that need to be organized and synthesized in such modular decision support system. Such improvement should focus on the inclusion of semantic annotations in CAD models (Boujut \& Hisarciklilar, 2012), the increase of flexibility of information exchange between modelling domains and the development of a 'meta- 
model' boundary object which enables to negotiate about the information requirements for a certain decision to be made.

Further work is needed to generalise the results of this study to other design contexts and processes. The product type of the investigated companies (i.e. earthmoving heavy equipment) drives the emphasis of certain aspects (e.g. functionality and performances) over others (e.g., serviceability). This may influence the negotiation behaviour, independently from the boundary objects used in the process. Suggestion for future work is to investigate such link through the use of an ethnographic approach performing a thematic analysis for data quantification.

\section{References}

Amadori, K., Tarkian, M., Ölvander, J., \& Krus, P. (2012). Flexible and robust CAD models for design automation. Advanced Engineering Informatics, 26(2), 180-195.

Barley, W. C., Leonardi, P. M., \& Bailey, D. E. (2012). Engineering objects for collaboration: Strategies of ambiguity and clarity at knowledge boundaries. Human communication research, 38(3), 280-308.

Bertoni, M., Panarotto, M., \& Larsson, T. C. (2016). Boundary objects for PSS design. Procedia CIRP, 47, 329-334.

Bharosa, N., Lee, J., Janssen, M., \& Rao, H. R. (2012). An activity theory analysis of boundary objects in cross-border information systems development for disaster management. Security Informatics, 1(1), 15.

Boujut, J. F., \& Blanco, E. (2003). Intermediary objects as a means to foster cooperation in engineering design. Computer Supported Cooperative Work (CSCW), 12(2), 205-219.

Boujut, J. F., \& Hisarciklilar, O. (2012). Using a semiotic classification to characterise objects involved in collaborative design. Journal of Design Research, 10(3), 155169.

Boujut, J. F., \& Laureillard, P. (2002). A co-operation framework for product-process integration in engineering design. Design studies, 23(6), 497-513. 
Bocken, N. M., de Pauw, I., Bakker, C., \& van der Grinten, B. (2016). Product design and business model strategies for a circular economy. Journal of Industrial and Production Engineering, 33(5), 308-320.

Bucciarelli, L. L. (2002). Between thought and object in engineering design. Design studies, 23(3), 219-231.

Carlile, P. R. (2002). A pragmatic view of knowledge and boundaries: Boundary objects in new product development. Organization science, 13(4), 442-455.

Cavalieri, S., \& Pezzotta, G. (2012). Product-Service Systems Engineering: State of the art and research challenges. Computers in industry, 63(4), 278-288.

Chandrasegaran, S. K., Ramani, K., Sriram, R. D., Horváth, I., Bernard, A., Harik, R. F., \& Gao, W. (2013). The evolution, challenges, and future of knowledge representation in product design systems. Computer-aided design, 45(2), 204-228.

Charnley, F., Lemon, M., \& Evans, S. (2011). Exploring the process of whole system design. Design Studies, 32(2), 156-179.

Ebert, C. (1997). Dealing with nonfunctional requirements in large software systems. Annals of Software Engineering, 3(1), 367-395.

Eckert, C. (2001). The communication bottleneck in knitwear design: analysis and computing solutions. Computer Supported Cooperative Work (CSCW), 10(1), 2974.

Eckert, C. M., \& Stacey, M. K. (2010). What is a process model? Reflections on the epistemology of design process models. In Modelling and Management of Engineering Processes (pp. 3-14). Springer, London.

Flanagan, T., Eckert, C., \& Clarkson, P. J. (2007). Externalizing tacit overview knowledge: A model-based approach to supporting design teams. AI EDAM, 21(3), 227-242.

Goodwin, R. S. (1993). Skills required of effective project managers. Journal of Management in Engineering, 9(3), 217-226.

Hazelrigg, G. A. (1998). A framework for decision-based engineering design. Journal of mechanical design, 120(4), 653-658.

Henderson, K. (1991). Flexible sketches and inflexible data bases: Visual communication, conscription devices, and boundary objects in design engineering. Science, Technology, \& Human Values, 16(4), 448-473. 
Iorio, J., \& Taylor, J. E. (2014). Boundary object efficacy: The mediating role of boundary objects on task conflict in global virtual project networks. International Journal of Project Management, 32(1), 7-17.

Isaksson, O., Larsson, T. C., \& Rönnbäck, A. Ö. (2009). Development of productservice systems: challenges and opportunities for the manufacturing firm. Journal of Engineering Design, 20(4), 329-348.

Johansson, C., Wall, J., \& Panarotto, M. (2017). Maturity of models in a multi-model decision support system. In 21st International Conference on Engineering Design (ICED), Vancouver (Vol. 6, pp. 237-246). The Design Society.

Kastensson, A., \& Johansson, C. (2011). Decision making in gates: based on formal basis or gut feeling?. International Journal of Technology Intelligence and Planning, 7(2), 140-152.

Kipouros, T., \& Isaksson, O. (2016, January). Visual analytics for evaluation of value impact in engineering design. In ECCOMAS Congress 2016-Proceedings of the 7th European Congress on Computational Methods in Applied Sciences and Engineering (Vol. 3, pp. 6461-6470).

Kleinsmann, M., \& Valkenburg, R. (2008). Barriers and enablers for creating shared understanding in co-design projects. Design studies, 29(4), 369-386.

Kokkolaras, M., Mourelatos, Z. P., \& Papalambros, P. Y. (2004, January). Design optimization of hierarchically decomposed multilevel systems under uncertainty. In ASME 2004 International Design Engineering Technical Conferences and Computers and Information in Engineering Conference (pp. 613-624). American Society of Mechanical Engineers.

Larsson, A. (2003, November). Making sense of collaboration: the challenge of thinking together in global design teams. In Proceedings of the 2003 international ACM SIGGROUP conference on Supporting group work (pp. 153-160). ACM.

Miles, M. B., Huberman, A. M., \& Saldana, J. (2013). Qualitative data analysis. London: Sage publications Ltd.

Mintzberg, H., Raisinghani, D., \& Theoret, A. (1976). The structure of" unstructured" decision processes. Administrative science quarterly, 246-275.

Neyland, D. (2008). Organizational Ethnography. London: Sage Publications Ltd.

Pahl, G., \& Beitz, W. (2013). Engineering design: a systematic approach. Springer Science \& Business Media. 
Perry, M., \& Sanderson, D. (1998). Coordinating joint design work: the role of communication and artefacts. Design studies, 19(3), 273-288.

Power, D. J., \& Sharda, R. (2007). Model-driven decision support systems: Concepts and research directions. Decision Support Systems, 43(3), 1044-1061.

Raudberget, D., Levandowski, C., Isaksson, O., Kipouros, T., Johannesson, H., \& Clarkson, J. (2015). Modelling and assessing platform architectures in preembodiment phases through set-based evaluation and change propagation. Journal of Aerospace Operations, 3(3, 4), 203-221.

Richards, M. G., Shah, N. B., Hastings, D. E., \& Rhodes, D. H. (2007, June). Architecture Frameworks in System Design: Motivation, Theory, and Implementation. In INCOSE International Symposium (Vol. 17, No. 1, pp. 981990).

Robson, C. (2002). Real world research (Second Edition). Oxford: Blackwell Publishing.

Sacks, R., Radosavljevic, M., \& Barak, R. (2010). Requirements for building information modeling based lean production management systems for construction. Automation in construction, 19(5), 641-655.

Saldaña, J. (2015). The coding manual for qualitative researchers. Newbury Park: Sage Publications Ltd.

Schleich, B., Anwer, N., Mathieu, L., \& Wartzack, S. (2017). Shaping the digital twin for design and production engineering. CIRP Annals, 66(1), 141-144.

Shankar, P., Morkos, B., \& Summers, J. D. (2010, January). A hierarchical modeling scheme with non functional requirements. In ASME 2010 International Design Engineering Technical Conferences and Computers and Information in Engineering Conference (pp. 283-295). American Society of Mechanical Engineers.

Simon, H. A. (1972). Theories of bounded rationality. Decision and organization, 1(1), 161-176.

Simon, H. A. (1979). Rational decision making in business organizations. The American economic review, 69(4), 493-513.

Star, S. L (2010). This is Not a Boundary Object: Reflections on the Origin of a Concept. Science, Technology, \& Human Values, 35 (5), 601-617. 
Star, S. L., \& Griesemer, J. R. (1989). Institutional ecology, 'translations' and boundary objects: Amateurs and professionals in Berkeley's Museum of Vertebrate Zoology, 1907-39. Social studies of science, 19(3), 387-420.

Strauss A. L., Corbin, J., M. (1990). Basics of qualitative research. Newbury Park: Sage Publications Ltd.

Tan, A. R., Matzen, D., McAloone, T. C., \& Evans, S. (2010). Strategies for designing and developing services for manufacturing firms. CIRP Journal of Manufacturing Science and Technology, 3(2), 90-97.

Thibaut, J. W., \& Walker, L. (1975). Procedural justice: A psychological analysis. L. Erlbaum Associates.

Ullman, D.G. (2003). The mechanical design process. New York: McGraw-Hill.

Wall, J., Larsson, T., \& Bertoni, M. (2018). A model-driven decision arena: Augmenting decision making in early design. DS 91: Proceedings of NordDesign 2018, Linköping, Sweden, 14th-17th August 2018.

White, D. D., Wutich, A. Y., Larson, K. L., \& Lant, T. (2015). Water management decision makers' evaluations of uncertainty in a decision support system: the case of WaterSim in the Decision Theater. Journal of Environmental Planning and Management, 58(4), 616-630.

Worinkeng, E., Joshi, S., \& Summers, J. D. (2015). An experimental study: analyzing requirement type influence on novelty and variety of generated solutions. International Journal of Design Creativity and Innovation, 3(2), 61-77. 